\title{
Bronchial asthma control degree and the temperament structure according to the Eysenck model
}

\author{
Andrzej Witusik', Lukasz Mokros², Piotr Kuna³, Tadeusz Pietras ${ }^{2}$
}

\begin{abstract}
'Department of Psychology, Institute of Pedagogical Sciences, Faculty of Social Science in Piotrkow Trybunalski Branch, Jan Kochanowski University in Kielce, Poland

${ }^{2}$ Department of Clinical Pharmacology, Medical University of Lodz, Barlicki Memorial Clinical Hospital No. 1, Lodz, Poland ${ }^{3}$ Department of Internal Medicine, Asthma and Allergy, Medical University of Lodz, Barlicki Memorial Clinical Hospital No. 1, Lodz, Poland
\end{abstract}

Adv Dermatol Allergol 2020; XXXVII (4): 559-565

DOI: https://doi.org/10.5114/ada.2019.83216

\begin{abstract}
Introduction: Asthma is a disease of a psychosomatic nature. The control of asthma is still poor in approximately $5 \%$ of patients, despite introduction of modern inhalant drugs and psychotherapeutic interventions.

Aim: To evaluate whether the degree of bronchial asthma control is related to the characteristics of temperament according to Eysenck's concept.

Material and methods: The study was conducted on a group of 111 bronchial asthma patients and 44 healthy subjects. In all of them, the Eysenck temperament questionnaire was administered and the level of asthma control was determined.

Results: Increase in the scale of neuroticism was associated with an 1.83-fold increase in the likelihood of poor asthma control. Increase in the result on the psychoticism scale and lie scale of about one point was associated with a slightly smaller increased risk of poor asthma control (respectively: 1.49-fold and 1.61-fold).

Conclusions: The structure of temperament of a person with poor control of bronchial asthma can be characterized. Patients with poor asthma control have a higher level of neuroticism, psychoticism and propensity to lie, compared with the healthy population and subjects with good or partial bronchial asthma control.
\end{abstract}

Key words: disease control, neuroticism, psychoticism, logistic models, personality.

\section{Introduction}

Bronchial asthma is a disease of inflammatory etiology, which affects $5-10 \%$ of the world's population [1, 2]. It develops most often in subjects with allergy resulting from eosinophilic or mixed cell bronchitis, or, much less frequently, as a result of a non-allergic inflammatory condition. The inflammatory mediators released by the cells cause reversible bronchospasms, clinically manifested by shortness of breath and the presence of wheezing and crackles [1, 2]. The regulation of bronchospasm is a process also indirectly related to the mediators secreted from the terminals of the vagal and sympathetic nerves [2]. These mediators interact not only with the bronchial smooth muscle, but also with lymphocytes, basophils and eosinophils, epithelial cells and mucous gland cells. Neural regulation of bronchospasm in an asthma attack cannot therefore be limited only to the impact of the mediators on the contraction/relaxation of the bronchial muscular layer [3]. In view of the above, the mental condition may exert an indirect modulatory effect on the symptoms and course of bronchial asthma. On the other hand, the attacks of bronchial asthma and their negative impact on the quality of life can affect the psychological status of the patients and their social functioning [4]. Therefore, the correlations that occur between the features of character, the psychological state of the individual and the course of bronchial asthma are complex. Asthma is obviously a disease of a psychosomatic nature, although its causes are disorders of regulation in the immune system most commonly associated with atopy and allergic inflammation of the tissue lining the bronchial tubes. The psychosomatic conditioning of bronchial asthma is evidenced even by the commonly known effect of stress on induction of dyspnea attacks, associated with hyperreactivity of the inflammation-affected bronchial

Address for correspondence: Lukasz Mokros MD, PhD, Department of Clinical Pharmacology, Medical University of Lodz, 22 Kopcinskiego St, 90-153 Lodz, Poland, phone: +48 4267821 29, e-mail: lukasz.mokros@umed.lodz.pl Received: 9.01.2019, accepted: 31.01.2019. 
mucosa and secondary hypersensitivity to cold air during emotion-induced hyperventilation [4, 5]. The psychosomatic nature of the disease does not undermine the concept of its inflammatory and immune background but rather points to the links between mental processes and the immune system in humans and to the validity of the psychoneuroimmunology paradigm.

Temperament is one of the important elements that modulate the impact of the psyche on the symptoms and course of somatic diseases and mental disorders [6]. The temperament is understood as the component of personality (regarded as a set of features of the individual that makes up the superior behavior-regulating system), which characterizes the ways of behavior and expression, rather than their content [6]. The temperament does not determine "what we do" but rather "how we do it". The temperament is to a large extent determined biologically - by the quotient of genetic and environmental factors affecting intrauterine fetal development, and indirectly the physiological properties of the brain [6]. The temperament is treated in clinical psychology and psychiatry as an important predictor of the occurrence of certain diseases, including primarily affective disorders and anxiety disorders. Such research was conducted for many years by Qiu et al. [7]. In the research conducted by our team, we have demonstrated repeatedly a relationship of temperament with the clinical presentation of bronchial asthma and chronic obstructive pulmonary disease using the original Polish idea of temperament as formal characteristics of behavior. The above theory was developed and popularized by Strelau. It is considered to be a significant contribution to the Polish psychological thought in the world psychology of individual differences. The concept of temperament developed by Eysenck is better known in psychological literature [6, 8, 9]. This approach treats the temperament as a synonym for the concept of personality. Using the factor analysis method, Eysenck distinguished three superfactors whose intensity characterizes the temperament of the individual - neuroticism, extraversion and psychoticism [6, 8, 9]. Neuroticism means a tendency to experience anxiety, tension and depression, extroversion is defined as the desire to make social contacts, whereas psychoticism is a tendency to aggression, coldness, self-centeredness, and lack of empathy $[6,8,9]$. Recently, the author has identified additional scales, determining: a tendency to develop addiction, a scale of lies and a tendency to commit crimes [10].

Research on the structure of temperament according to the Eysenck model in the context of bronchial asthma has been scarce, although Neuroticism as a Big Five component was previously associated with perceived poor asthma control [11]. Also, high negative emotionality, a dimension of type $D$ behavior and a construct similar to neuroticism, was found to be associated with poor asthma control in one of our previous studies [12].
Currently, asthma is a disease that is usually well controlled and does not impair the quality of life so much as it used to before the introduction of inhaled medications that control the course of bronchial asthma, primarily glucocorticoids and to a lesser degree leukotriene receptor antagonists. However, the control of asthma is still poor in approximately $5 \%$ of patients, despite more and more modern inhalant drugs and effective psychoeducation [13]. The question arises as to whether temperamental personality factors as defined by Eysenck are related to poor asthma control.

\section{Aim}

The purpose of this study was to evaluate whether the level of bronchial asthma control is related to the characteristics of temperament according to Eysenck's concept. Based on the current literature we hypothesized that poor asthma control may be associated with high indices of neuroticism and psychoticism.

\section{Material and methods}

\section{Study group and procedure}

The research was conducted on a group of $111 \mathrm{sub}$ jects with bronchial asthma aged 20-60 years, patients of the outpatient asthma treatment department of Norbert Barlicki Memorial University Clinical Hospital No. 1. The control group consisted of 44 healthy individuals. The main inclusion criterion was giving informed consent in a written form. Patients with cancer, chronic obstructive pulmonary disease, systemic connective tissue diseases, a past acute coronary episode during the last 6 months, and those experiencing intensive stress due to mourning, surgery or job loss, were excluded from the study. Subjects above 60 years of age were also excluded. The degree of bronchial asthma control was determined using the Asthma Control Test $[13,14]$. In the Asthma Control Test, consisting of five questions, the score of 25 points was regarded as good control of asthma, the result of 20-24 points was regarded as partial control and 20 points or less as poor control. Poor control of asthma was diagnosed in 31 subjects, partial control in 27, and good control in 60. The studied groups did not differ significantly in the demographic variables, as presented in Table 1.

To measure the temperament factors, the latest validated and standardized Polish language version of the EPQ-R Eysenck temperament questionnaire, published by the Psychological Tests Laboratory of the Polish Psychological Association in 2011, was used [10]. It measures the following scales: psychoticism, extroversion, neuroticism, lies, susceptibility to addiction and propensity to crime. 
Table 1. Comparison of the age and the results on the Eysenck Personality Questionnaire Revised scales between the sexes in the studied population sample

\begin{tabular}{|c|c|c|c|c|c|c|}
\hline \multirow[t]{2}{*}{ Parameter } & \multicolumn{2}{|c|}{ Women $(n=77)$} & \multicolumn{2}{|c|}{ Men $(n=78)$} & \multirow[t]{2}{*}{$F$} & \multirow[t]{2}{*}{$P$-value } \\
\hline & Mean & SD & Mean & SD & & \\
\hline Age & 33.43 & 9.51 & 32.65 & 9.37 & 0.261 & 0.61 \\
\hline Neuroticism & 9.62 & 5.30 & 9.73 & 4.94 & 0.017 & 0.896 \\
\hline Extraversion & 13.94 & 3.02 & 14.12 & 3.19 & 0.131 & 0.718 \\
\hline Psychoticism & 8.32 & 3.59 & 8.94 & 3.41 & 1.182 & 0.279 \\
\hline Lie & 10.43 & 2.74 & 10.64 & 3.14 & 0.201 & 0.654 \\
\hline $\begin{array}{l}\text { Susceptibility to } \\
\text { addictions }\end{array}$ & 9.43 & 2.34 & 8.81 & 2.55 & 2.498 & 0.116 \\
\hline Propensity to crime & 9.74 & 3.29 & 9.61 & 3.06 & 0.064 & 0.8 \\
\hline
\end{tabular}

$S D$ - standard deviation, F-F test statistic in the analysis of variance, $p$ - probability in the F test, or Welch test, depending on the fulfillment of assumptions concerning the homogeneity of variance in the groups.

The consent for the study of the Bioethics Committee of the Medical University of Łódź NoRNN/133/09/ KE was obtained.

\section{Statistical analysis}

Statistical analysis was performed using the SPSS 24 PL software package (IBM, United States). The mean values and standard deviations were used to characterize the continuous variables. Due to the sample size $(n=155)$, limit theorems were used and verification of the hypothesis of normality of distribution of continuous variables was abandoned. The hypothesis of homogeneity of variance of continuous variables in groups identified on the basis of the asthma control level was verified by means of the Levene test. Comparisons between groups (two or more than two) were performed by analysis of variance (F) with a post-hoc Tukey test in the case of a decision that the assumption of variance homogeneity was fulfilled. Otherwise, Welch test with the post-hoc Dunnett T3 test was used. The relationship between two continuous variables was assessed using the Pearson correlation coefficient. A logistic regression model was constructed to assess the relationship between the intensity of EPQ-R personality traits and the probability of poor asthma control. A collective test of the model factors was used for global verification of the model. Logistic regression results were presented as the odds ratio (OR) with $95 \%$ confidence intervals. The level of statistical significance $\alpha=0.05$ was adopted.

\section{Results}

There were no differences in the mean age of women and men or in the intensity of temperament dimensions in the analyzed population (Table 1).

The intensity of neuroticism was lower in the group of healthy subjects, as well as patients with well-controlled and partly controlled asthma compared to those with poor asthma control (Figure 1). Psychoticism was

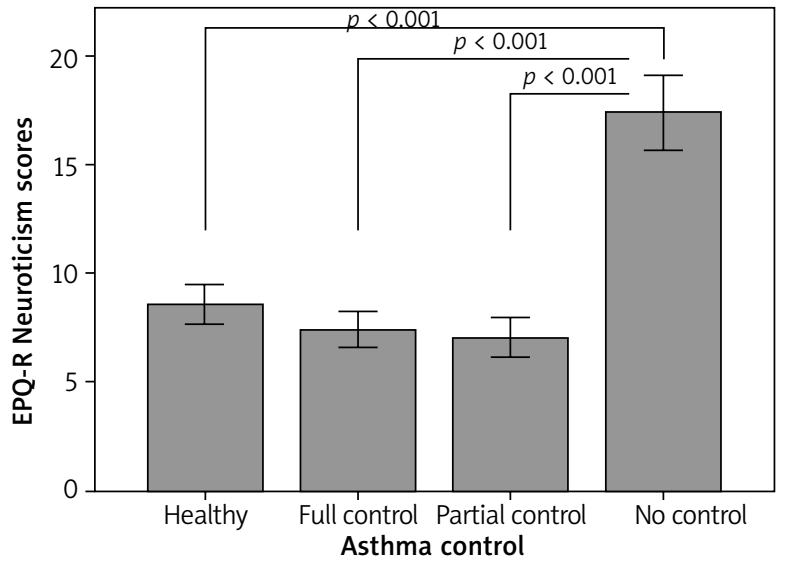

Presented as mean values (bars) with 95\% confidence intervals (whiskers). $p$-probabilities in the post-hoc tests.

Figure 1. Comparison of the Eysenck Personality Questionnaire - Revised (EPQ-R) Neuroticism scores between the healthy sample and asthma control groups

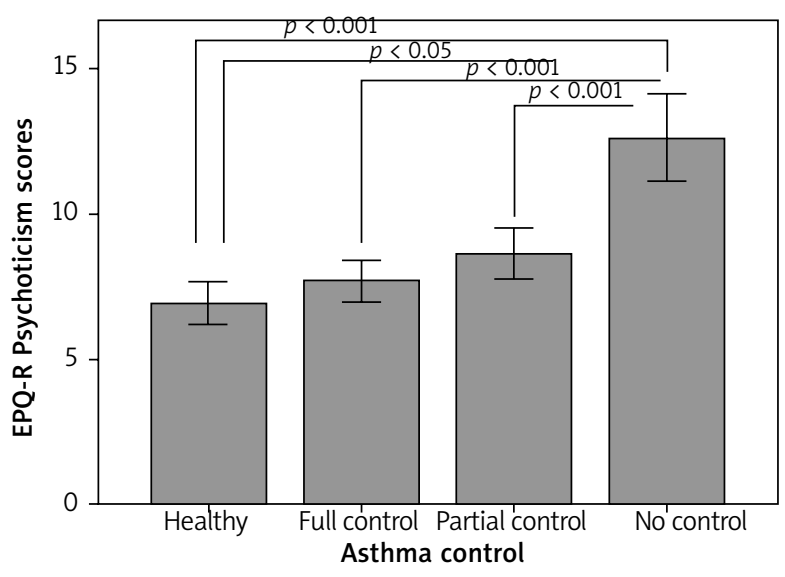

Presented as mean values (bars) with 95\% confidence intervals (whiskers). $p$-probabilities in the post-hoc tests.

Figure 2. Comparison of the Eysenck Personality Questionnaire - Revised (EPQ-R) Psychoticism scores between the healthy sample and asthma control groups 
Table 2. Comparison of the age and the results on the Eysenck Personality Questionnaire Revised scales between the groups designated by the degree of asthma control in the studied population sample

\begin{tabular}{|c|c|c|c|c|c|c|c|c|c|c|}
\hline \multirow[t]{3}{*}{ Parameter } & \multirow{2}{*}{\multicolumn{2}{|c|}{$\begin{array}{l}\text { Healthy subjects } \\
\qquad(n=44)\end{array}$}} & \multicolumn{6}{|c|}{ Asthma control level } & \multirow[t]{3}{*}{$F$} & \multirow[t]{3}{*}{$P$-value } \\
\hline & & & \multicolumn{2}{|c|}{ Full control $(n=52)$} & \multicolumn{2}{|c|}{ Partial control $(n=28)$} & \multicolumn{2}{|c|}{ No control $(n=31)$} & & \\
\hline & Mean & SD & Mean & SD & Mean & SD & Mean & SD & & \\
\hline Age & 32.23 & 10.49 & 32.63 & 9.47 & 32.04 & 7.96 & 35.77 & 8.85 & 1.121 & 0.343 \\
\hline Neuroticism & $8.57^{\star}$ & 3.06 & $7.42^{\star}$ & 2.97 & $7.04^{\star}$ & 2.32 & 17.42 & 4.63 & 43.544 & $<0.001$ \\
\hline Extraversion & 13.82 & 3.53 & 13.87 & 2.62 & 14.54 & 3.41 & 14.13 & 2.98 & 0.373 & 0.773 \\
\hline Psychoticism & $6.91^{\star, \star \star}$ & 2.44 & $7.71^{\star}$ & 2.50 & $8.64^{\star}$ & 2.26 & 12.61 & 4.12 & 16.537 & $<0.001$ \\
\hline Lie & $10.09^{\dagger}$ & 3.12 & $10.12^{\dagger}$ & 3.12 & $9.93^{+}$ & 1.74 & 12.42 & 2.54 & 7.299 & $<0.001$ \\
\hline $\begin{array}{l}\text { Susceptibility to } \\
\text { addictions }\end{array}$ & 8.57 & 2.57 & 9.04 & 2.47 & 9.21 & 2.01 & 9.94 & 2.53 & 1.946 & 0.125 \\
\hline Propensity to crime & 9.14 & 2.42 & 9.17 & 2.89 & 10.11 & 3.36 & 10.87 & 4.02 & 2.567 & 0.057 \\
\hline
\end{tabular}

Table 3. Pearson correlation coefficients between the selected continuous variables

\begin{tabular}{lllllll}
\hline & Age & $\mathbf{1}$ & $\mathbf{2}$ & $\mathbf{3}$ & $\mathbf{4}$ & $\mathbf{5}$ \\
\hline Neuroticism & 0.065 & & & & & \\
\hline Extraversion & 0.019 & -0.011 & & & & \\
\hline Psychoticism & 0.032 & $0.570^{\star \star}$ & -0.022 & & & \\
\hline Lie & 0.109 & $0.179^{\star}$ & 0.083 & 0.113 & & \\
\hline Susceptibility to addictions & 0.065 & $0.197^{\star}$ & 0.099 & $0.207^{\star *}$ & $0.179^{\star}$ & \\
\hline Propensity to crime & 0.090 & $0.202^{*}$ & 0.055 & $0.219^{\star \star}$ & 0.090 & $0.429^{\star \star}$ \\
\hline
\end{tabular}

${ }^{*} p<0.01$ (two-tailed), ${ }^{* *} p<0.05$ (two-tailed).

found to be lower in the healthy controls and patients with good or partial asthma control compared to those with no control of bronchial asthma (Figure 2). Also in the lie scale score healthy subjects, well-controlled and partly controlled asthma patients demonstrated lower intensity than those with poorly controlled asthma (Table 2).

In the studied group, neuroticism correlated positively with the level of psychoticism, the lie scale, susceptibility to addiction and propensity to crime. Psychoticism, in turn, correlated with the lie scale, susceptibility to addiction and propensity to crime. The lie scale score correlated positively with susceptibility to addiction, and susceptibility to addiction with propensity to crime (Table 3).

\section{Association between the temperament factors according to the EPQ-R model and the probability of poor asthma control}

The classification based on the developed logistic regression model was valid for $84 \%$ of patients with poorly controlled asthma, and for $97.5 \%$ of those without asthma or with well- or partly controlled asthma (Figure 3). An increase in the neuroticism scale score by one point was associated with a 1.83-fold increase in the probability of poor asthma control. The result on the psychoticism and lie scales increased by one point was associated with a slightly smaller increase in the risk of poor asthma control (1.49-fold and 1.61-fold, respectively). The exact results of the logistic regression are provided in Table 4. These correlations were independent of the sex and age of the patients.

\section{Discussion}

In our study, poor asthma control was found to be correlated with high intensity of the psychoticism, neuroticism and lie dimension. It can therefore be attempted to determine the temperament profile of a subject with poor asthma control.

High neuroticism means a tendency to depression and anxiety. Indeed, numerous other studies have confirmed that individuals with poor asthma control tend to be anxious and depressive $[4,5,15]$. Sastre et al. have demonstrated that anxiety, depressiveness and a low forced expiratory volume in $1 \mathrm{~s}\left(\mathrm{FEV}_{1}\right)$ value are independent risk factors for poor asthma control [16]. Also in many other studies it has been shown that anxiety and depression correlate with poor asthma control [15, 17, 18]. Our study has demonstrated a similar correlation, using the Polish version of the Eysenck questionnaire. It should 
Table 4. Results of the logistic regression model assessing the correlation between the probability of poor asthma control and the indicated continuous variables in the studied population sample

\begin{tabular}{lllllc}
\hline Parameter & OR & & $95 \% \mathrm{Cl}$ & Wald & $P$-value \\
\hline Male gender & 0.41 & 0.07 & 2.53 & 0.917 & 0.338 \\
\hline Age & 1.05 & 0.96 & 1.15 & 1.142 & 0.285 \\
\hline Neuroticism & 1.83 & 1.34 & 2.51 & 14.247 & $<0.001$ \\
\hline Extraversion & 1.06 & 0.75 & 1.49 & 0.119 & 0.730 \\
\hline Psychoticism & 1.49 & 1.10 & 2.01 & 6.592 & 0.010 \\
\hline Lie & 1.61 & 1.12 & 2.30 & 6.583 & 0.010 \\
\hline Susceptibility to addictions & 0.93 & 0.62 & 1.39 & 0.120 & 0.729 \\
\hline Propensity to crime & 1.08 & 0.79 & 1.47 & 0.227 & 0.633 \\
\hline
\end{tabular}

$O R$ - odds ratio, $C$ - confidence interval, Wald - Wald statistic, $p$ - probability in the test.

be considered why poor control of asthma is related to neuroticism. Poor control of the disease means its severe course, the presence of dyspnea attacks, limitation of activity, and secondary anxiety and depression [4, 5]. Thus, poorly controlled asthma can be viewed as a strong stresor that interferes with the functioning of the human being and leads to emotional disorders $[11,19]$. On the other hand, chronic allergic inflammation of the bronchial mucous membrane is the source of inflammatory mediators which can induce functional changes in the central nervous system resulting in the development of emotional disorders [20, 21]. In particular, inteleukin 5 may be a link between allergic inflammation and the development of emotional disorders, which has been demonstrated by Elomaa et al. From another point of view, high intensity of neuroticism promotes hyperventilation with cold air under stress, which induces attacks of dyspnea and worsening of asthma control [22]. In this case, the mechanism of dyspnea attacks resembles the mechanism of exercise-induced bronchospasm [23]. Depressive and anxious subjects may also use the rescue therapy inadequately to the needs, which paradoxically may also worsen asthma control [24]. The correlation of high neuroticism with poor asthma control, demonstrated by us, requires further research regarding the mechanisms underlying that relationship.

We have also observed that subjects with poor asthma control demonstrate higher psychoticism and lie scale scores. The psychoticism factor in the Eysenck model was originally constructed to measure the tendency to mental disorders. Individuals with a high level of the psychoticism dimension are aggressive, antisocial, cold, self-centered, and impulsive [25]. Such instability of the temperament and a tendency to lie (cheat) can result in instability of compliance with medical recommendations and irregularity of the medication. However, this is only a hypothesis which needs to be verified. On the other hand, a severe course of the disease characterized by variability of clinical signs and their unpredictability may create an image of mental instability. Such instabil-

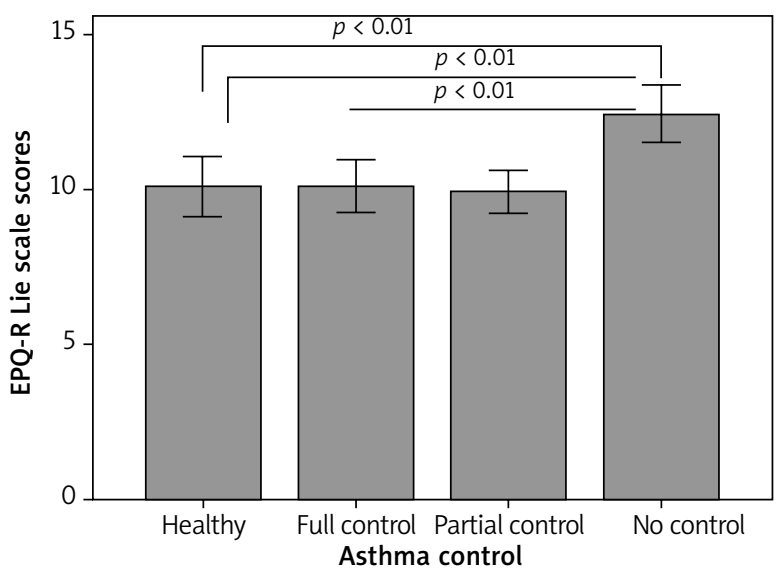

Presented as mean values (bars) with 95\% confidence intervals (whiskers). $p$ - probabilities in the post-hoc tests.

Figure 3. Comparison of the Eysenck Personality Questionnaire - Revised (EPQ-R) Lie scale score scores between the healthy sample and asthma control groups

ity in the course of the disease may be, at least in theory, primary to mental instability. However, a high value of the lie scale score suggests rather the inverse relationship, i.e. the effect of high psychoticism on the instability of clinical presentation of the disease and its poor control. Our results, however, require multiple verification on larger groups, because research by Gulec et al. conducted in patients with asthma, psoriasis and healthy controls by using temperament questionnaires were carried out on too small patient populations [26]. Tests carried out according to Cloninger's method revealed significantly lower Novelty Seeking, higher Harm Avoidance, lower Reward Dependence, and higher Self-transcendence scores in patients with asthma. On the other hand, studies on asthma patients using the Minnesota Multiphasic Personality Inventory have shown that they have relatively higher inactivity, anergy, feeling of guilt, pessimism, nonspecific physical ailments, and irrational fears. To some 
extent, the above results confirm our observation, although they were obtained using different tools and on a group consisting of only 33 patients with asthma and 20 healthy subjects with introversion [27]. High psychoticism level according to the Eysenck model is to some extent coincident with dissocial personality traits, although extreme characteristics of correctly shaped personality cannot be equated with a personality disorder [6, 25] Indeed, there are studies indicating the association of dissocial personality with bronchial asthma [28]. This observation, however, requires verification using epidemiological studies, which have not been conducted.

In our group of asthma patients, neuroticism correlated positively with psychoticism, lying, susceptibility to addictions and propensity to crime. In the standardization group of the Polish version of the Eysenck questionnaire, neuroticism and psychoticism, as well as components of the latter, were independent variables [10]. This is probably due to the fact that patients with poor asthma control are likely to show high values of neuroticism and psychoticism, as well as components of the latter. Indeed, a longitudinal prospective study on a population of 12 thousand confirmed the association of neuroticism with the development and course of bronchial asthma [29]. Such studies, however, were not conducted for the psychological construct of psychoticism according to the Eysenck model because it used a questionnaire designed based on the Big Five model of personality. Presuming with some approximation that high psychoticism according to the Eysenck model means a high level of openness to experience and low agreeableness and conscientiousness [6], that study fails to confirm our observation concerning the association of asthma with psychoticism. On the other hand, a study by Loerbroks et al. assessed the association of asthma with the personality traits and not with the degree of asthma control [29]. Perhaps the additional high value of the psychoticism dimension determines poor control of the course of the disease in neurotic subjects with asthma, as the psychological profile of a person with poor control of asthma which emerges from our research is a neurotic person with considerable intensity of psychoticism traits, including a propensity to lie.

\section{Conclusions}

Based on our research, the structure of temperament of a person with poor control of bronchial asthma can be characterized. Patients with poor asthma control have a higher level of neuroticism, psychoticism and propensity to lie, compared with the healthy population and subjects with good or partial bronchial asthma control. In the group of asthma patients, the intensity of neuroticism correlates positively with that of psychoticism and its components.

\section{Acknowledgments}

The contribution of the first author amounts to $80 \%$.

The study was funded by Medical University of Lodz institutional grant no. 503/1-151-07/503-16-001.

\section{Conflict of interest}

The authors declare no conflict of interest.

\section{References}

1. Kim H, Ellis AK, Fischer D, et al. Asthma biomarkers in the age of biologics. Allergy Asthma Clin Immunol 2017; 13: 48.

2. Barnes PJ. Cellular and molecular mechanisms of asthma and COPD. Clin Sci 2017; 131: 1541-58.

3. McGovern AE, Mazzone SB. Neural regulation of inflammation in the airways and lungs. Auton Neurosci Basic Clin 2014; 182: 95-101.

4. Panek M, Pietras T, Witusik A, et al. Identification and association of relationships between selected personal and environmental factors and formal components of temperament and strategies of coping with stress in asthmatic patients. Physiol Behav 2015; 149: 269-78.

5. Panek M, Jonakowski M, Zioło J, et al. Identification of relationships between interleukin 15 mRNA and brain-derived neurotrophic factor II mRNA levels with formal components of temperament in asthmatic patients. Mol Neurobiol 2017; 54: 1733-44

6. Strelau J. Różnice indywidualne. Historia - determinanty zastosowania. Wydawnictwo Naukowe SCHOLAR, Warsaw 2015.

7. Qiu F, Akiskal HS, Kelsoe JR, et al. Factor analysis of temperament and personality traits in bipolar patients: correlates with comorbidity and disorder severity. J Affect Disord 2017; 207: 282-90.

8. Eysenck HJ. Genetic and environmental contributions to individual differences: the three major dimensions of personality. J Pers 1990; 58: 245-61.

9. Grossarth-Maticek R, Eysenck HJ. Personality, stress and disease: description and validation of a new inventory. Psychol Rep 1990; 66: 355-73.

10. Jaworowska A. EPQ-R - Kwestionariusz Osobowości Eysencka EPQ-R, Kwestionariusz Osobowości Eysencka w Wersji Skróconej EPQ-R(S). Pracownia Testów Psychologicznych Polskiego Towarzystwa Psychologicznego, Warsaw 2011.

11. Cheung MMY, LeMay K, Saini B, et al. Does personality influence how people with asthma manage their condition? J Asthma 2014; 51: 729-36.

12. Witusik A, Mokros $Ł$, Kosmalski M, et al. Type D personality and the degree of control of bronchial asthma. Adv Dermatol Allergol 2018; 35: 387-91.

13. Global Initiative for Asthma. 2018 GINA Report, Global Strategy for Asthma Management and Prevention. 2018. Available from: https://ginasthma.org/.

14. Juniper EF, Byrne PM, Guyatt GH, et al. Development and validation of a questionnaire to measure asthma control. Eur Respir J 1999; 14: 902 LP-907.

15. Adewuya AO, Adeyeye OO. Anxiety and depression among Nigerian patients with asthma: association with sociodemographic, clinical, and personality factors. J Asthma 2017; 54: 286-93. 
16. Sastre J, Crespo A, Fernandez-Sanchez A, et al. Anxiety, depression, and asthma control: changes after standardized treatment. J Allergy Clin Immunol Pract 2018; 6: 1953-9.

17. Merghani TH, Alawad AO. Indicators of asthma control in asthmatic patients: are they related to depression? Open Access Maced J Med Sci 2017; 5: 673-6.

18. Shams MR, Bruce AC, Fitzpatrick AM. Anxiety contributes to poorer asthma outcomes in inner-city black adolescents. J Allergy Clin Immunol Pract 2018; 6: 227-35.

19. Panek M, Kuna P, Witusik A, et al. Temperament and stress coping styles in bronchial asthma patients. Adv Dermatol Allergol 2016; 33: 469-74.

20.Sanna L, Stuart AL, Pasco JA, et al. Atopic disorders and depression: findings from a large, population-based study. J Affect Disord 2014; 155: 261-5.

21. Elomaa AP, Niskanen L, Herzig KH, et al. Elevated levels of serum IL-5 are associated with an increased likelihood of major depressive disorder. BMC Psychiatry 2012; 12: 2.

22. Hallstrand TS. New insights into pathogenesis of exerciseinduced bronchoconstriction. Curr Opin Allergy Clin Immunol 2012; 12: 42-8

23. Kippelen P, Anderson SD, Hallstrand TS. Mechanisms and biomarkers of exercise-induced bronchoconstriction. Immunol Allergy Clin North Am 2018; 38: 165-82.

24. Baddar S, Jayakrishnan B, Al-Rawas OA. Asthma control: importance of compliance and inhaler technique assessments. J Asthma 2014; 51: 429-34.

25. Strelau J. Psychologia temperamentu. Wydawnictwo Naukowe PWN, Warsaw 2009.

26. Gulec MY, Gulec H, Oztuna F, et al. Cloninger's temperament and character dimension of personality in patients with asthma. Int J Psychiatry Med 2010; 40: 273-87.

27. Bulcun E, Turkel Y, Oguztürk O, et al. Psychological characteristics of patients with asthma. Clin Respir J 2016; 12: 113-8.

28. Wamboldt MZ, Weintraub P, Krafchick D, et al. Psychiatric family history in adolescents with severe asthma. J Am Acad Child Adolesc Psychiatry 1996; 35: 1042-9.

29. Loerbroks A, Li J, Bosch JA, et al. Personality and risk of adult asthma in a prospective cohort study. J Psychosom Res 2015; 79: $13-7$. 